\title{
Ophthalmology on social networking sites: an observational study of Facebook, Twitter, and Linkedln
}

This article was published in the following Dove Press journal:

Clinical Ophthalmology

10 February 2015

Number of times this article has been viewed

\author{
Jonathan A Micieli ${ }^{1}$ \\ Edmund $\mathrm{Tsui}^{2}$ \\ 'Department of Ophthalmology and \\ Vision Sciences, University of Toronto, \\ Toronto, ON, Canada; ${ }^{2}$ Department \\ of Surgery, Dartmouth-Hitchcock \\ Medical Center, Lebanon, NH, USA
}

Background: The use of social media in ophthalmology remains largely unknown. Our aim was to evaluate the extent and involvement of ophthalmology journals, professional associations, trade publications, and patient advocacy and fundraising groups on social networking sites.

Methods: An archived list of 107 ophthalmology journals from SCImago, trade publications, professional ophthalmology associations, and patient advocacy organizations were searched for their presence on Facebook, Twitter, and LinkedIn. Activity and popularity of each account was quantified by using the number of "likes" on Facebook, the number of followers on Twitter, and members on LinkedIn.

Results: Of the 107 journals ranked by SCImago, 21.5\% were present on Facebook and $18.7 \%$ were present on Twitter. Journal of Community Eye Health was the most popular on Facebook and JAMA Ophthalmology was most popular on Twitter. Among the 133 members of the International Council of Ophthalmology, 17.3\% were present on Facebook, 12.8\% were present on Twitter, and 7.5\% were present on LinkedIn. The most popular on Facebook was the International Council of Ophthalmology, and the American Academy of Ophthalmology was most popular on Twitter and LinkedIn. Patient advocacy organizations were more popular on all sites compared with journals, professional association, and trade publications. Among the top ten most popular pages in each category, patient advocacy groups were most active followed by trade publications, professional associations, and journals.

Conclusion: Patient advocacy groups lead the way in social networking followed by professional organizations and journals. Although some journals use social media, most have yet to engage its full potential and maximize the number of potential interested individuals.

Keywords: social media, Twitter, Facebook, LinkedIn, ophthalmology

\section{Introduction}

Social networking sites such as Facebook, Twitter, and LinkedIn are increasingly attracting the attention of physicians intrigued by their potential and reach. As of June 2014, Facebook had 1.32 billion monthly active users and 1.07 billion monthly users active on mobile devices worldwide. ${ }^{1}$ Similarly, enormous numbers are seen with Twitter and LinkedIn, with 271 million monthly active users and more than 313 million registered members, respectively. ${ }^{2,3}$ Facebook, Twitter, and LinkedIn involve creating a personal profile where the individual can share a variable amount of personal information and content to his or her "friends" or "followers". Each member can choose to passively receive content on their news feed that is of interest to them by "liking" an organization or individual on Facebook or "following" an account on Twitter or LinkedIn. This content can subsequently be shared or commented on by each user, allowing for a vast amount of easily accessible information to be disseminated
Correspondence: Jonathan A Micieli Department of Ophthalmology and Vision Sciences, University of Toronto, 340 College Street, Suite 400, Toronto, Ontario, M5T 3A9 Toronto, ON M5T 2S8, Canada

$\mathrm{Tel}+\mathrm{I} 4169786294$

Fax +I 9053034700

Email jonathan.micieli@utoronto.ca (c) (i) (5) 2015 Micieli and Tsui. This work is published by Dove Medical Press Limited, and licensed under Creative Commons Attribution - Non Commercial (unported, v3.0) BY LC License. The full terms of the license are available at http://creativecommons.org/licenses/by-nc/3.0/. Non-commercial uses of the work are permitted without any further permission how to request permission may be found at: http://www.dovepress.com/permissions.php 
among individuals who may not otherwise interact in person or online.

With such a wide potential audience, it is no surprise that use of social networking has exponentially increased in the health care sector. In May 2012, the official New England Journal of Medicine Twitter account (@nejm) had 66,000 followers, which has grown to 218,000 in October 2014. ${ }^{4}$ Moreover, the number of peer-reviewed articles reviewing the use of social media in medicine and proposing novel ways to utilize social networking sites has also grown over the past few years. These novel uses include the creation of conference-specific "hashtags" to allow for interaction among conference attendees, ${ }^{5}$ the development of new metrics to measure the impact of peer-reviewed publications, ${ }^{6}$ and novel modalities to rapidly gauge public opinion regarding a health-related topic. ${ }^{4}$ Twitter and mobile technology have also been used as diagnostic aids and emergency modes of communication during natural disasters. ${ }^{7,8}$ Accordingly, professional medical associations have adopted formal policies to promote the responsible use of social media by physicians. ${ }^{9}$

The use of social networking sites in the field of ophthalmology remains unknown. One previous publication discussed the use of Twitter as a tool for ophthalmologists and reviewed the most popular ophthalmology-related feeds on this social networking site at the time. ${ }^{4}$ However, this study served more as an introduction to Twitter and did not assess the use of other sites, such as Facebook or LinkedIn on ophthalmology-related topics. Previous studies have quantified the use of social networking sites in dermatology, ${ }^{10}$ but there remains little information on other areas in medicine. It is unknown to what degree peer-reviewed journals and professional associations in ophthalmology have engaged social media and which social networking site is preferred. A low level of participation may stimulate journals, organizations, and patient advocacy groups to take a renewed interest in social networking sites to increase their overall impact. Authors may prefer to submit their work to a journal with a strong presence on these sites so that their work may reach a broader audience. The goal of this study was to evaluate and quantify the extent of involvement of peer-reviewed journals, professional organizations, trade publications, and patient advocacy organizations in ophthalmology on Facebook, Twitter, and LinkedIn.

\section{Materials and methods}

To determine the presence of ophthalmology journals on social networking sites, an archived list of 107 ophthalmology journals was assembled using the SCImago journal ranking search on October 14, 2014. ${ }^{11}$ Journals were retrieved using the following search criteria: medicine (subject), ophthalmology (subject category), all countries, 2014 (year), and no minimal citations. Each ophthalmology journal was then searched on Facebook and Twitter using the full journal name and abbreviations in the search box of each site. Furthermore, the official website of each journal was observed for links to any social networking pages. Popularity of the audience for each account was quantified by recording the number of "likes" on Facebook or "followers" on Twitter. Only official organization pages were included and links to other third party information sites on Facebook were excluded.

All professional ophthalmology associations were included in the study if they were members of the International Council of Ophthalmology (ICO) or listed on the ICO website. ${ }^{12}$ Additional associations were retrieved by searching the official associations of each peer-reviewed journal and examining the follower list of other professional organizations on Twitter. Ophthalmology trade publications or magazines published in the English language were retrieved from Google searches, the collective personal experience of the authors, and by searching the follower list of each retrieved trade publication and ophthalmology professional association on Twitter. Patient advocacy groups, defined as educational, patient support, or fundraising organizations for visually impaired people, were retrieved using American Academy of Ophthalmology (AAO) links to humanitarian organizations and resources for patients. ${ }^{13,14}$ The followers of each organization on Twitter were further searched to retrieve additional organizations not on the AAO list. In addition to assessing the popularity on Facebook and Twitter, professional ophthalmology associations and patient advocacy groups were also searched on LinkedIn with the number of "members" recorded to quantify popularity on this site. English language only searches were performed for all journals and organizations.

Box and whisker plots using Tukey's method were created using GraphPad Prism version 6.00 for Macintosh (GraphPad Software, La Jolla, CA, USA). These plots were used to compare the top ten ranking accounts in each category: peer-reviewed journals, trade publications, professional associations, and patient advocacy or fundraising groups. The central box represents the values from the 25 th to 75 th percentiles and the middle line represents the median value. The whisker lines extend from the minimum to the maximum values, excluding outliers (defined as greater than 
or less than $1.5 \times$ interquartile range), which are displayed as separate points.

\section{Results}

Of the 107 ophthalmology journals ranked by SCImago, only $21.5 \%$ were present on Facebook and $18.7 \%$ were present on Twitter. Only $46 \%$ of journals with a Facebook or Twitter page had a link posted on their official website. Moreover, only three and five of the top ten ranked journals by SCImago were present on Facebook and Twitter, respectively. The Journal of Community Eye Health garnered the most followers on Facebook whereas JAMA Ophthalmology had the most followers on Twitter. Among the 133 members of the ICO, only $18 \%$ were present on Facebook, $12.8 \%$ were present on Twitter, and $7.5 \%$ were present on LinkedIn. The ICO had the most followers on Facebook and the AAO had the most followers on Twitter. Table 1 displays the three most popular journals, trade publications, professional associations, and patient advocacy groups on Facebook, Twitter, and LinkedIn.

Patient advocacy groups were the most popular on Facebook, with the leader, The Fred Hollows Foundation (an Australian foundation named after an Australian ophthalmologist), having 60,000 more likes than the leading professional ophthalmology association, the International Council of Ophthalmology (Figure 1). Patient advocacy organizations were similarly more popular than journals, professional associations, and trade publications on Twitter (Figure 2); however, the leading professional association, the AAO, had more followers than all patient advocacy organizations except for the Royal National Institute for the Blind. Moreover, patient advocacy groups were more popular on LinkedIn (Figure 3) than with professional organizations despite the AAO being the leader with 4,608 followers. The median number of followers on Facebook among the top ten peer-reviewed journals was greater than those of trade

Table I Top three most popular accounts on each social media platform (Facebook, Twitter, Linkedln) of peer-reviewed journals, professional organizations, trade publications, and patient advocacy groups

\begin{tabular}{|c|c|c|c|}
\hline \multicolumn{4}{|l|}{ Peer-reviewed journals } \\
\hline Journal & Facebook likes & Journal & Twitter followers \\
\hline Journal of Community Eye Health & 3,989 & JAMA Ophthalmology & 4,623 \\
\hline Optometry and Vision Science & 3,009 & British Journal of Ophthalmology & 2,997 \\
\hline JAMA Ophthalmology & 2,453 & Ophthalmic Surgery Lasers and Imaging & 1,064 \\
\hline \multicolumn{4}{|l|}{ Professional organizations } \\
\hline Association & Facebook likes & Organization & Twitter followers \\
\hline International Council of Ophthalmology & $\mathrm{II}, 872$ & American Academy of Ophthalmology & $\mathrm{II}, 800$ \\
\hline American Academy of Ophthalmology & 8,409 & $\begin{array}{l}\text { Association for Research in Vision } \\
\text { and Ophthalmology }\end{array}$ & 6,374 \\
\hline Women in Ophthalmology & 2,273 & $\begin{array}{l}\text { American Society of Cataract } \\
\text { and Refractive Surgery }\end{array}$ & 3,524 \\
\hline Association & LinkedIn members & & \\
\hline American Academy of Ophthalmology & 4,608 & & \\
\hline $\begin{array}{l}\text { Association for Research in Vision } \\
\text { and Ophthalmology }\end{array}$ & 1,259 & & \\
\hline International Council of Ophthalmology & 1,216 & & \\
\hline \multicolumn{4}{|l|}{ Trade publications } \\
\hline Publication & Facebook likes & Publication & Twitter followers \\
\hline Eyetube.net & 4,132 & Ophthalmology Times Europe & 8,788 \\
\hline Ophthalmology Times & 2,673 & Ocular Surgery News & 7,531 \\
\hline Review of Ophthalmology & 1,609 & Eyetube.net & 6,517 \\
\hline \multicolumn{4}{|l|}{ Patient advocacy groups } \\
\hline Association & Facebook likes & Association & Twitter followers \\
\hline The Fred Hollows Foundation & 72,698 & Royal National Institute of Blind People & 22,900 \\
\hline Sightsavers & 56,058 & Sightsavers & 9,096 \\
\hline OneSight & 29,587 & Canadian National Institute of the Blind & 8,888 \\
\hline Association & LinkedIn members & & \\
\hline Royal National Institute of Blind People & 2,889 & & \\
\hline The Fred Hollows Foundation & 2,388 & & \\
\hline Canadian National Institute of the Blind & 1,920 & & \\
\hline
\end{tabular}




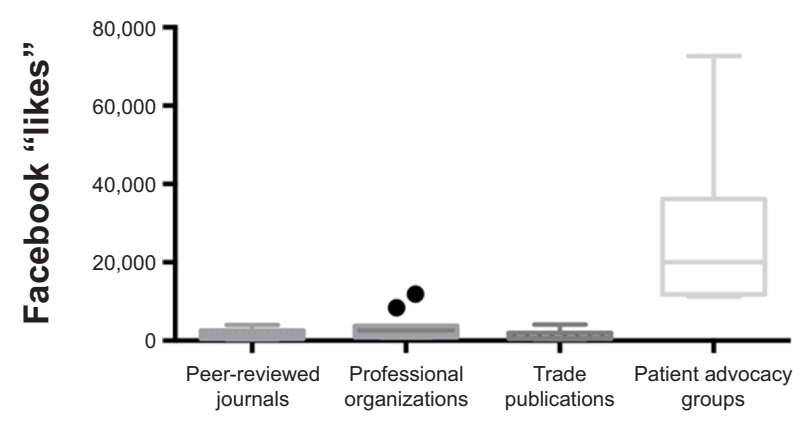

Figure I Box and whisker plots depicting the number of Facebook "likes" for peer-reviewed journals, professional organizations, trade publications, and patient advocacy groups.

Notes: The central box represents values from the 25th to 75 th percentiles and the middle line represents the median value. Whisker lines extend from minimum to maximum values, excluding outliers (which are displayed as separate points).

publications (1,345 versus 902). However, the top ten trade publications were more popular on Twitter, with a median number of followers of 5,015 compared with 821.5 for peerreviewed journals.

The activity on Twitter was quantified using the number of tweets by each organization or publication. Among the top ten most popular in each category, patient advocacy organizations were the most active (median number of tweets $3,608)$ followed by trade publications $(1,247.5)$, professional associations (823), and journals (584.5). The number of tweets among the ten most popular accounts in each group is displayed in Figure 4.

\section{Discussion}

Our results show that, at the present time, a small proportion of ophthalmology journals are active on social networking sites and follow behind patient advocacy organizations, trade publications, and professional associations. Given that the AAO had a total of 11,800 followers on Twitter and more than 25,000 general members, this comprises a large

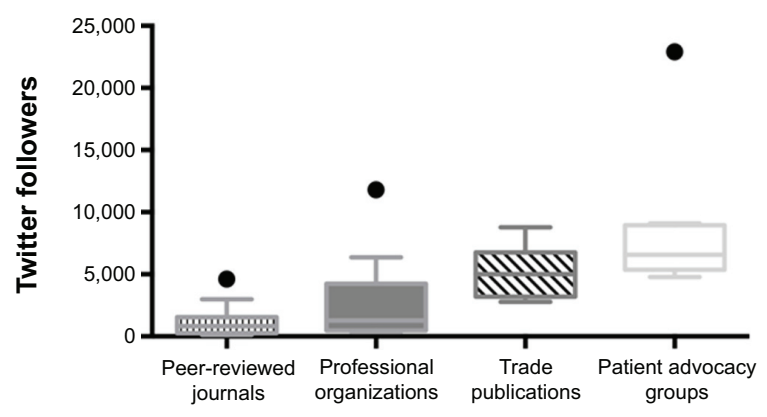

Figure 2 Box and whisker plots depicting the number of Twitter followers for peer-reviewed journals, professional organizations, trade publications, and patient advocacy groups.

Notes: The central box represents values from the 25 th to 75 th percentiles and the middle line represents the median value. Whisker lines extend from minimum to maximum values, excluding outliers (which are displayed as separate points).

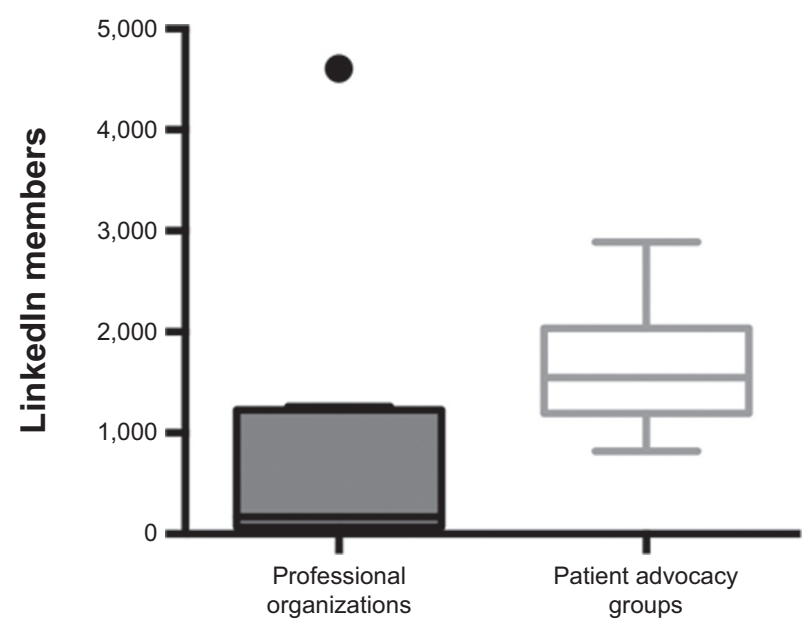

Figure 3 Box and whisker plots depicting the number of Linkedln members for professional organizations and patient advocacy groups.

Notes: The central box represents values from the 25 th to 75 th percentiles and the middle line represents the median value. Whisker lines extend from minimum to maximum values, excluding outliers (which are displayed as separate points).

potentially interested audience that has yet to be engaged by general ophthalmology journals. A potential way to increase followers is by posting links to social networking sites on the official websites of ophthalmology journals, which was done by less than half of the journals included in this study. Social media leaders, including the AAO and large meetings such as the World Ophthalmology Congress, advertise their social media presence via email and through their official website with "follow us" links. This medium is advertised as the most rapid way to stay up to date at their sponsored meetings, and this likely contributes to their large number of followers. Other potential ways to increase the number of followers include posting interesting items that may be "re-tweeted" or shared by large, popular groups or directing posts to popular accounts that may share these interactions with their large audience. ${ }^{4}$ In addition, following others on

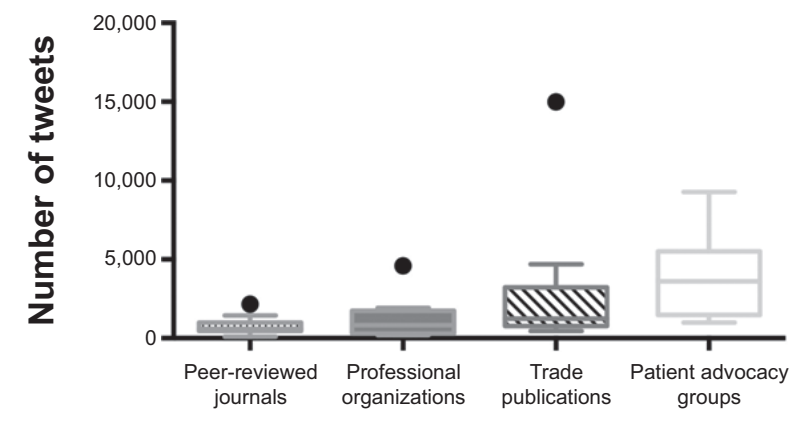

Figure 4 Box and whisker plots depicting the activity of peer-reviewed journals, professional organizations, trade publications, and patient advocacy groups on Twitter.

Notes: The central box represents values from the 25 th to 75 th percentiles and the middle line represents the median value. Whisker lines extend from minimum to maximum values, excluding outliers (which are displayed as separate points). 
social networking sites may also be reciprocated by another account. As evidenced by general medical journals, such as the New England Journal of Medicine, which has over one million "likes" on Facebook, social media is a novel avenue to increase interest in a professional journal.

Patient advocacy groups had the largest presence on all social networking sites. This is most likely because they are appealing to the general public and not necessarily to ophthalmic professionals. Most tweets and posts from these organizations centered on educational events, fundraising opportunities, and recent advances in eye research. Many of these organizations also interact with each other such that their posts and tweets are shared amongst each other's followers. This helps to grow each other's audience, since followers of each organization are made aware of the other's presence. Moreover, patient advocacy groups had a larger presence on Facebook compared with Twitter and LinkedIn. This may be a result of Facebook being established earlier in 2004 compared with Twitter in 2006 and a larger membership base of Facebook compared with both Twitter and LinkedIn. ${ }^{1-3}$ A similar trend was not seen with ophthalmology journals; in fact, ophthalmology trade publications had a stronger presence on Twitter compared with Facebook. This may be a result of these organizations being more active on Twitter and the more concise nature of Twitter's 140-character messages that may appeal to medical professionals. In addition, LinkedIn is a business-oriented social networking site rather than one appealing to the general public, which may reflect its lesser popularity compared with Facebook and Twitter.

There remains little information on the use of social networking sites among other fields of medicine at the present time. A previous publication looking at dermatology organizations also found that patient advocacy organizations were more active on social media compared with journals and professional organizations. ${ }^{10}$ Given the time-sensitive information of recording the popularity of each group on social media, it is difficult to compare the popularity of these groups from 2012 to present ophthalmology organizations. However, there is a growing body of evidence that social media use in medicine is growing substantially each year. At the American Urology Association and Canadian Urology Association annual meetings there was a dramatic increase in the number of tweets at the 2013 meeting compared with the previous year. ${ }^{15}$ The Lancet and JAMA have grown from 36,733 and 18,422 followers in May 2012 to 142,000 and 95,600 in October $2014 .{ }^{4}$ An analysis of urology journals on Twitter found that the presence of an account on this site was associated with a higher impact factor, and these high impact journals have turned to social networking sites to reveal new articles in their publications. ${ }^{16}$ With a growing online presence, organizations have also turned to online journal clubs on Twitter to discuss important articles internationally and foster future collaboration. ${ }^{17}$

To our knowledge, this is the first report to evaluate the presence of ophthalmology journals, professional associations, trade publications, and patient advocacy groups on different social media platforms. Our study was limited in that only accounts in the English language were included, which may have led to an underestimation of the number of ICO professional associations and patient advocacy groups found on social networking sites. Moreover, the social networking accounts of publishing companies were not included in the study. Although these accounts may discuss topics related to their associated ophthalmology journal, they focused on a much broader medical audience than a dedicated ophthalmology journal account would. Finally, the evolution of each account over time was not considered, which may have led to emerging accounts being overlooked when only the raw number of followers were considered. Although we evaluated three of the most popular sites, other platforms such as Instagram, Pinterest, and Google+ were not studied. Future studies should aim to assess measures of engagement (characteristics of engaged users), content analysis (what material is being shared by users), and measures of overlap (whether journals, organizations, and trade publications are following each other). Although it remains unknown whether social media impact is also a driver for more tangible impact, such as citations for peer-reviewed publications, it is not difficult to imagine how social media activity can help reach and engage a larger audience than more traditional methods.

In conclusion, social networking sites have evolved into an important medium for the discussion of medical issues and have been adopted by the highest impact journals. At the present time, only a minority of ophthalmology journals are active on Facebook, Twitter, and LinkedIn, and follow behind patient advocacy organizations and professional associations. There is a large potential audience following professional organizations such as the AAO that has not been attracted to peer-reviewed journals as yet. Novel uses of social media, such as international journal groups and conference-specific "hashtags", are gathering momentum and may become the standard mode of communication at specific events. With continued technological evolution, journals and organizations that fail to recognize the opportunity afforded by social media risk becoming marginalized in an increasingly competitive environment. 
Patient advocacy organizations are leaders in the use of social media among ophthalmology groups, as evidenced by their popularity and activity. The former may be a result of their broader audience that includes the general public rather than a defined group of ophthalmology professionals. Certain professional ophthalmology associations have adopted social media and have a large following but still have the potential for growth. Further studies should aim to address the differences in content between the posts of different organizations and factors determining the popularity of social networking sites.

\section{Acknowledgment}

The authors would like to thank Jie Deng for her help in preparing the manuscript and figures.

\section{Author contributions}

Study conception and design (JAM, ET), data collection and analysis (JAM, ET), preparation of manuscript (JAM, ET), and final review (JAM, ET). JAM and ET had full access to all of the data in the study and takes responsibility for the integrity of the data and the accuracy of the data analysis.

\section{Disclosure}

The authors report no conflicts of interest in this work.

\section{References}

1. Facebook. Newsroom. Available from: http://newsroom.fb.com/ company-info/. Accessed October 16, 2014.

2. Twitter. About Twitter. Available from: https://about.twitter.com/ company_Accessed October 16, 2014.
3. LinkedIn. About LinkedIn. Available from: http://press.linkedin.com/ about. Accessed October 16, 2014.

4. Micieli R, Micieli JA. Twitter as a tool for ophthalmologists. Can J Ophthalmol. 2012;47(5):410-413.

5. Mishori R, Levy B, Donvan B, Twitter use at a family medicine conference: analyzing \#STFM13. Fam Med. 2014;46(8):608-614.

6. Cress PE. Using altmetrics and social media to supplement impact factor: maximizing your article's academic and societal impact. Aesthet Surg J. 2014;34(7):1123-1126.

7. Tamura Y, Fukuda K. Earthquake in Japan. Lancet. 2011;377(9778): 1652.

8. Leow JJ, Groen RS, Sadasivam V, Kushner AL. Twitter and mobile technology as diagnostic aids in the Democratic Republic of Congo. Am Surg. 2011;77(11):E242-E243.

9. American Medical Association. AMA Policy: Professionalism in the use of social media. Accessed October 16, 2014. Available from: https:// www.adventisthealth.org/nw/Documents/AMA-Professionalism-inuse-of-Social-Media-7-25-11.pdf. Accessed October 16, 2014.

10. Mahsa A, Sampson BP, Endly D, et al. Social networking sites: emerging and essential tools for communication in dermatology. JAMA Dermatol. 2014;150(1):56-60.

11. SCImago Journal and Country Rank. 2014. Available from: http:// www.scimagojr.com/journalrank.php?area $=2700 \&$ category $=2731 \&$ country $=$ all\&year $=2013 \&$ order $=$ sj $\&$ min $=0 \&$ min $\_$type $=$cd. Accessed October 14, 2014.

12. International Council of Ophthalmology. ICO members. Available from: http://www.icoph.org/advancing_leadership/ophthalmologic_societies. html. Accessed October 18, 2014.

13. American Academy of Ophthalmology. International eye care organizations. Available from: http://www.aao.org/international/humanitarian/ links.cfm. Accessed October 18, 2014.

14. American Academy of Ophthalmology. Resourced for your patients. Available from: http://www.aao.org/practice_mgmt/patient_ed/ resource.cfm. Accessed January 10, 2015.

15. Matta R, Doiron C, Leveridge MJ. The dramatic increase in social media in urology. J Urol. 2014;192(2):494-498.

16. Nason G, O'Kelly F, Kelly M, et al. The emerging use of Twitter by urological journals. BJU Int. June 13, 2014. [Epub ahead of print].

17. Thangasamy IA, Leveridge M, Davies BJ, Finelli A, Stork B, Woo HH. International Urology Journal Club via Twitter: 12-month experience. Eur Urol. 2014;66(1):112-117.
Clinical Ophthalmology

\section{Publish your work in this journal}

Clinical Ophthalmology is an international, peer-reviewed journal covering all subspecialties within ophthalmology. Key topics include: Optometry; Visual science; Pharmacology and drug therapy in eye diseases; Basic Sciences; Primary and Secondary eye care; Patient Safety and Quality of Care Improvements. This journal is indexed on Submit your manuscript here: http://www.dovepress.com/clinical-ophthalmology-journal

\section{Dovepress}

PubMed Central and CAS, and is the official journal of The Society of Clinical Ophthalmology (SCO). The manuscript management system is completely online and includes a very quick and fair peer-review system, which is all easy to use. Visit http://www.dovepress.com/ testimonials.php to read real quotes from published authors. 